\section{MARÍA PILAR SINUÉS, DE LA PROVINCIA A LA CAPITAL DEL REINO}

\author{
Leonardo Romero Tobar
}

Universidad de Zaragoza
Cómo citar este artículo/Citation: Romero Tobar, L. (2014). "María Pilar Sinués, de la provincia a la capital del reino". Arbor, 190 (767): a141. doi: http://dx.doi.org/10.3989/ arbor.2014.767n3012

Recibido: 3 julio 2013. Aceptado: 6 abril 2014.

RESUMEN: María del Pilar Sinués fue autora de un centenar de publicaciones y de la fórmula "ángel del hogar", clave para entender su éxito de lectores y la ideología de la domesticidad en España. Aquí se estudia su actividad en Zaragoza (cinco años) y su éxito en Madrid, proporcionado por sus habilidades literarias y la red de relaciones profesionales que tejió. En esta tarea se sirvió de los contactos sociales de su esposo, de los salones sociales y, fundamentalmente, de la prensa periódica.

PALABRAS CLAVE: Pilar Sinués; ideología doméstica; campo literario de las ciudades; red de relaciones literarias; salones sociales; prensa periódica.

\section{MARÍA PILAR SINUÉS, FROM THE PROVINCES TO THE CAPITAL OF THE KINGDOM}

Copyright: (c) 2014 CSIC. Este es un artículo de acceso abierto distribuido bajo los términos de la licencia Creative Commons Attribution-Non Commercial (by-nc) Spain 3.0.
ABSTRACT: María Pilar Sinués was the author of approximately a hundred publications. She created the term "angel del hogar" (angel of the home), the key to her success among readers, and of the ideology of domesticity in Spain. This article studies her early works in the provincial city of Zaragoza and her literary success in Madrid, enabled by her literary talent and the network of professional contacts she built. To this end, she drew upon her husband's social contacts, social gatherings and, above all, newspapers.

KEYWORDS: Pilar Sinués; domestic ideology; literary field of the cities; network of literary contacts; social gatherings; periodicals. 
Las primeras publicaciones de María Pilar Sinués (Zaragoza, 1835 - Madrid, 1893) ofrecen en la portada la denominación de la autora como "la señorita Da María Pilar Sinués y Navarro" para, a partir de 1856 desaparecer el apellido materno que es sustituido por "Señora ... de Marco", una onomástica que se formaliza definitivamente solo con el primer apellido, el paterno Sinués, a partir del año $1876^{1}$. Estas modificaciones en la firma de la prolífica escritora responden, como es sabido, a las variaciones de su estado civil: soltera, casada y separada. Una definición jurídica en los dos primeros casos que responde al fundamento sociológico de las funciones que asignaba a las mujeres la sociedad del siglo XIX. En la definición de estas situaciones, Pilar Sinués, precisamente, representó un papel capital a través de sus escritos narrativos, didácticos y de prosa periodística, en los que troqueló la fórmula ángel del hogar para definir el estereotipo de comportamiento de la mujer como hija, esposa y madre, las tres ocupaciones femeninas modélicas ${ }^{2}$. Pero, por si esta fórmula no tuviera suficiente capacidad publicitaria, la escritora zaragozana publicó el año 1863 otra obra de construcción ideológica que tituló Hija, esposa y madre: cartas dedicadas a la mujer acerca de los deberes para con la familia y la sociedad, libro que fue otro éxito de librería ya que recibió siete ediciones posteriores. Siguieron varios libros estrictamente educativos o de lo que ahora se denominaría de "autoayuda": Un libro para las damas (1875), Un libro para las madres (1877), La mujer en nuestros días (1878), Un libro para las jóvenes (1879).

El éxito de las citadas publicaciones y del casi centenar de las distintas obras que salieron de su pluma ${ }^{3}$ habla muy elocuentemente del ajuste de las propuestas de la escritora a los valores establecidos en la sociedad coetánea y de las habilidades de su escritura, recursos ambos con los que cautivaba el interés de su abundante público lector. La aceptación lectora explica las constantes reediciones y el que la autora siguiera en activo hasta dos años antes de su muerte. De todas formas, los cambios axiológicos y de gustos literarios experimentados en el último tercio del siglo XIX dieron pie al alejamiento del público más exigente, distancia que puede sintetizar el siguiente texto crítico que firmaba el joven Leopoldo Alas en uno de sus artículos de El Solfeo (“Manos blancas”, 11-II-1876):

Siempre me ha parecido un borrón en las hermosas páginas del libro de Heine De la Alemania las bromas que se permite el gran poeta con Madame Staël acerca de sus relaciones literarias con Schlegel y los otros románticos. La sátira personal no puede llegar a la mujer, so pena de incurrir en grosería el autor satírico. Fundado en esto, aunque siento en el alma que una ilustre escritora, la señora doña María del Pilar Sinués, haya encontrado agradabilísma lectura en Las Llaves de Teodoro Guerrero, pues esto es condenarme a mí, que las he juzgado muy malas llaves, no por ello he de salirme de mis casillas, ni del decoro debido; que desde que estudié primeras letras -y cuenta que las estudié en tiempos en que se pagaba a los maestros- he aprendido reglas de buena crianza, entre otras, el siguiente pareado, que dicho sea de paso, arde en un candil: En si hace o no la dama su calceta/ el cumplido galán nunca se meta (Alas, 2002, V, p. 367).

El implícito acuerdo sobre el papel social que debía representar la mujer en la sociedad isabelina, puesta al servicio de la domesticidad hogareña, explica el crecimiento del número de escritoras que trabajaron al servicio de ese programa ideológico. Este fenómeno social y literario es ampliamente conocido en las literaturas de lengua inglesa, francesa y alemana, y para la literatura en español ya cuenta con un amplio elenco de estudios generales y monográficos sobre autoras y asuntos desarrollados en la prensa femenina $y$ los libros educativos del siglo XIX $\mathrm{X}^{4}$. Lo mismo puede decirse de la aplicación del modelo folletinesco a las narraciones en las que se vertía este adoctrinamiento de pretendida liberación, un modelo de narración que Pilar Sinués cultivó con dedicación continuada (Romero Tobar, 1976, pp. 102, 124, 138, 143-145, 149 y 201).

De autora tan significativa me interesa aquí indagar cómo cambió su primer escenario provinciano de Zaragoza por la productiva fábrica para escritores que era el Madrid de mediados del siglo XIX con la finalidad de explicar en esa trayectoria los modos de funcionamiento de los espacios literarios en un corte diacrónico determinado: el segundo tercio del siglo XIX. Pues, si en ciudades que habían mantenido tradición de actividad literaria -imprentas acreditadas desde el siglo XVI, academias del Barroco, tertulias de ilustrados del XVIII, publicaciones periódicas románticas (AA. VV., 1988)-, podía desarrollarse un clima de producción y consumo de textos, la centralización nacional concentrada en Madrid hipertrofió la capacidad resonante de la capital del Reino, que se convirtió en el imprescindible escenario que determinaba el campo literario en lengua española (Romero Tobar, 2003).

\section{LOS COMIENZOS LITERARIOS EN LA CIUDAD PROVIN- CIANA}

Los primeros datos seguros que poseemos acerca de la actividad literaria de Pilar Sinués son de los 
años 1853 y 1854, en los que publicó once poemas en el diario zaragozano El Avisador y cinco en El Esparterista (Agudo Catalán, 2008, pp. 202, 220-221 y 250-251), poemas de temática religiosa, familiar e, incluso, política, ya que el 27-VII-1854 daba a luz en el primer periódico una "Poesía al invicto Duque de la Victoria" con la que culminaba una fase de exaltación esparterista vivida en Zaragoza y de la que dan testimonio otros poemas suyos aparecidos también en El Avisador. No tiene, pues, nada de extraño que en los años del sexenio revolucionario Pilar Sinués hiciera declaraciones en favor de las propuestas progresistas (especialmente en su revista El Ángel del Hogar). Con todo, el clima dominante de valores sociales la profesionalizó en una escritura domesticada que fue la línea dominante en toda su carrera literaria.

Confesiones autobiográficas en novelas, dedicatorias y artículos de periódicos dibujan su etapa infantil y de primera educación, escolarizada en el convento de Santa Rosa, un convento situado entonces extramuros de la ciudad y en el que se escenifica la etapa de educación de la protagonista de la novela Margarita $(1857)^{5}$. Novicia o educanda ${ }^{6}$ - el convento se abrió como colegio en 1781-, Pilar Sinués realizaría allí las primeras lecturas que la espolearon, sin duda, a la acción de escribir, ya que de su novela Rosa (1857) recuerda en El ángel del Hogar lo siguiente:

Recuerdo que cuando hace ocho años escribí y di a luz mi novela Rosa, mi primer ensayo en este género de literatura, nadie quiso creer [que] fuese obra mía no obstante ser tan sencilla como una rosa de invierno. Yo vi a Rosa en mi ciudad natal, en las manos del pobre artesano, en el tocador de la elegante dama, en el pupitre del respetable padre de familia, en la cocina del campesino y en la humilde habitación del virtuoso eclesiástico, pero todas estas gentes, si por acaso se alzaba entre ellas alguna voz que al verme pasar decía: esa es la autora de Rosa, mecían la cabeza con incredulidad, murmurando esa niña no puede haber escrito ese libro, será obra de su padre (p. 76).

Esta afirmación del año 1859 retrotrae al lector al año 1851, cuando la novelista contaba dieciocho años, antes incluso de la publicación de los poemas citados ${ }^{7}$. Esta precocidad literaria se desplegaba en el ámbito del hogar paterno, donde incluso la animosa joven practicaba la escritura clandestina pues, como afirma en la obra citada "salía del sueño a las tres o las cuatro de la mañana [...] y me ponía a escribir en pedazos de papel de todas clases, tamaños y colores, porque entonces yo carecía ihasta de papel!"8. Alguna toleran- cia debían de aplicar sus padres sobre esta práctica ya que en la edición de Rosa de 1857 les dedica la novela en estos términos: "A D. Pedro Sinués y Yoldi y doña Flora Navarro de Sinués.- Cuando viviendo a la sombra de vuestro amparo, escribí este pequeño libro [...] Madrid, 30 de enero de 1857". Una dedicatoria hecha en Madrid cuando ya había contraído matrimonio con el periodista y autor teatral valenciano José Marco Sanchís, al que dirige otra dedicatoria confesional en su edición de Margarita (2a edición, 1857):

Este libro lo escribí pensando en ti, y a ti lo dediqué cuando brotó en mi corazón el amor que te profeso. Hija de familia, entonces, robaba al sueño las horas que consagraba a Margarita, y durante las largas veladas de un invierno que empleé en este trabajo, yo te veía enfrente de mí, y a tu querida sombra invocaba sin cesar y pedía inspiración. Margarita, pues, es tuya; la amante te la dedicó, y hoy, hoy que con tanto orgullo se llama tu esposa, te la ofrece tu MARIA.- Madrid, septiembre de 1856

La cronología de las publicaciones y de los textos escritos en Zaragoza por nuestra autora abarca un arco de cinco años, desde 1851 hasta finales de 1855, ya que en las "Dos palabras que pueden servir de prólogo" a Margarita afirmaba que "cuando a finales del pasado año de 1855 terminé esta novela en Zaragoza, rogué al señor don José Marco, director de la revista de Bellas Artes La España Musical y Literaria, que a la sazón se publicaba en esta corte, y mi amigo entonces, que amparase mi obra, con un prólogo que quería deber a su pluma". Con todo, las referencias a su autobiografía literaria inducen a confusiones, como ocurre en la confesión que hace a Carolina Coronado en la dedicatoria de Premio y castigo (1857) al referirse a "los dos años que hace cruzo la espinosa senda literaria". Durante estos cinco o seis años nuestra autora publicó, además de los poemas aparecidos en periódicos, los siguientes libros que llevan pie de imprenta de Zaragoza: la no encontrada primera edición de Rosa, el poemario Mis vigilias (imprenta de Cristóbal Juste y Olona, 1854), el relato en prosa Luz de luna._Leyenda histórica del siglo XV (imprenta de Ramón León, 1855), La Princesa de los Caspios (imprenta de Ramón León, 1855) ${ }^{9}$.

Las dedicatorias que Sinués incluye en los libros publicados antes y en torno a la fecha de su matrimonio implican una comunicación directa con algunos escritores jóvenes de su ciudad natal, como es el caso de las que dirige en dos de las tres leyendas que conforman el libro poético Cantos de mi lira (1857), publicado ya en Madrid: "El Palacio de los Genios" dirigido a 
"mi querida hermana y amiga la distinguida y malograda poetisa Srta. D. a María Verdejo y Durán" y la del tercer relato versificado "Las dos sultanas" para don Joaquín de Urgellés, oscuro escritor local redactor de El Saldubense (1857-1862) y secretario del Liceo zaragozano (Guía de Zaragoza..., 1860, pp. 490-491). Pero otras figuras literarias de proyección nacional fueron también destinatarios de las primeras dedicatorias de nuestra autora. En 1855 encaminaba su Luz de luna a la protección de Gregorio Romero Larrañaga al que manifiesta haber leído con satisfacción su narración fantástica Amar con poca fortuna ${ }_{2}$ y al dirigir Premio y castigo (1857) a Carolina Coronado pondera dos obras de la extremeña, la Jarilla y la Sigea.

A las lecturas aludidas en las páginas preliminares de sus primeros libros es preciso sumar las citas en exergo que inician capítulos de estas primeras obras, citas que corresponden a escritores españoles -Gertrudis Gómez de Avellaneda, Carolina Coronado, Zorrilla- pero, sobre todo, a los autores franceses que ocupaban la pantalla romántica de máxima difusión a mediados del siglo, y en esta biblioteca de sus lecturas aparecen mezclados los católicos emocionales con los heterodoxos combativos: Lamartine y Lamennais, Chateaubiand y Eugène Sue, Nodier y los primeros realistas como Balzac ${ }^{10}$. Este brevísima anotación de estímulos literarios coloca a Pilar Sinués en la encrucijada del Romanticismo entre el idealismo nacionalista de los Schlegel y el socialismo consolador del autor de Les Mystères de Paris, en un cruce de tendencias que explica también el inmóvil moderantismo de la escritora y su aceptable visión de Espartero y lo que la política progresista significó.

Ahora bien, el hecho capital que reconduce los tanteos literarios e ideológicos de la escritora en su juvenil etapa zaragozana se produce con motivo de su boda con José de Marco y su traslado a la capital del Reino, a partir de 1856, momento en el que se abren los múltiples caminos de relación social que han de ser para ella la mejor "network" para la difusión de su fama. El primer apoyo, por supuesto, el matrimonio con un joven escritor que luchaba por la conquista de la capital desde los periódicos y desde los peldaños de la Administración.

La instalación madrileña de la Sinués no supuso un olvido de las gentes y lugares con quienes había vivido sus primeros años. Las dedicatorias personales antes citadas ${ }^{11}$ documentan su relación personal con escritores de su misma procedencia geográfica ${ }^{12}$, y en el plano de su escritura se proyectan sobre sus páginas figuras aragonesas como Agustina de Aragón -he- roína de un romance suyo impreso en Barcelona- y, por supuesto, los paisajes naturales de la tierra a los que se suma la identificación con los tópicos valores identitarios de Aragón. Iñigo Sánchez Llama (2000, 331-333) ha señalado un grupo de novelas a las que denomina "ciclo de novelas aragonesas" que fueron apareciendo a lo largo de la carrera editorial de nuestra autora: Margarita (1857, 2a ed.), El lazo de flores (1862), La rama de sándalo (1862), Celeste (1862), EI almohadón de la rosa (1864), El becerro de oro (1875), La misión de la mujer (1888). Para el citado estudiosos este conjunto de novelas, técnicamente muy cercanas al estilo narrativo de Fernán Caballero, "recrea una idílica sociedad de pequeños propietarios cuya estabilidad radica en el puntual seguimiento de las costumbres patriarcales y cristianas".

En Margarita leemos párrafos como este que pondera la belleza natural del campo: "todos los que hayan atravesado mi hermoso y risueño Aragón, habrán visto con placer la fertilidad de sus campiñas, sus caudalosos ríos y su azulado cielo; todos, estoy cierta, habrán admirado esta rica vegetación que da una idea tan magnífica del poder del Criador" (cap. 9). Y en otros varios en los que se ponderan las virtudes de sus habitantes, como en este caso: "[mi padre] asegura que es el país más rico en nobleza y lealtad que ha conocido. En otras partes, dice, hay nobles y plebeyos, en Aragón son todos aristócratas por el corazón" ( $p$. 217). Encomios que subraya la canción de un "gondolero de Nápoles" "[sic] en el curso de un viaje de los protagonistas a las tierras de Italia:

Blanca y dulce paloma

detén el raudo vuelo,

y el puro, hermoso cielo

no olvides de Aragón ( p. 127).

En estas novelas aragonesas, cuando la acción está ambientada en Zaragoza, el discurso narrativo solo enuncia topónimos de la ciudad (El Coso, La Seo, la alameda de El Carmen, el convento de Santa Rosa...), mientras que en las novelas cuyo marco es Madrid, las viviendas particulares y los lugares públicos van descritos con algún detalle en el que se subraya la connotación económico-social del lugar: para la aristocracia la calle de Alcalá o las calles del Carmen y del Ave María para la clase media. Sorprende la parquedad descriptiva de los escenarios urbanos en una escritora que en sus poemas se expande en las descripciones del paisaje natural y que en los relatos novelescos se demora en la pintura notarial de los interiores domésticos y los atuendos de los personajes. 
Compárese la descripción de dos interiores familiares. En primer lugar el gabinete de una casa de la burguesía media: "La habitación estaba revestida de un papel de color de lila claro con grandes arabescos blancos; una silla de tapicería de los mismos colores, una consola de limonero y un bonito espejo dorado componían su mueblaje; delante del balcón caían cortinas de muselina blanca, y una ancha copa de bronce llena de fuego daba, a falta de chimenea, calor a la habitación". Y seguidamente, el arranque del demorado dibujo de un salón aristocrático: "Las paredes vestidas de una tela de raso azul de cielo, recamada de diminutas flores de un azul más oscuro, armonizaban perfectamente con la sillería del mismo color y con la alfombra blanca con flores azules; de igual género eran las cortinas “[...]" (Premio y castigo, 1857, pp. 116 y 79).

\section{EL VIAJE A MADRID Y LA BODA (1856)}

Es suficientemente conocido, gracias a los recuerdos de Julio Nombela en sus Impresiones y recuerdos, que la carta de declaración amorosa que suscitó su matrimonio fue escrita al alimón por el grupo de poetas bohemios formado por José Marco, Gustavo Adolfo Bécquer, Luis García Luna y Juan Antonio Viedma: "En una de las noches en que nos encontrábamos en el café de San Antonio, hizo Viedma grandes elogios de una poesía que había leído en un periódico literario de Zaragoza, firmada por una joven que, en su concepto, estaba llamada a adquirir fama en cuanto fuese conocida. Llevaba el periódico, nos leyó los versos, que en efecto revelaban inspiración, y Marco dijo de pronto: Se me ocurre una idea.- ¿Cuál?- Casarme con esa mujer" (Nombela, 1976, p. 445).

No da Nombela la fecha exacta de la boda, aunque recuerda que fue hecha "por poderes" $y$, a falta de investigación documental, puede servir para datarla de modo aproximado el soneto que Quintana dedicó a nuestra autora, un poema en cuyos endecasílabos el laureado vate afirmaba "vas, amable Pilar, a ser esposa,/ consagrando en las aras de Himeneo/ tu libertad y gracias juveniles"; el poema está fechado en 10 de enero de $1856^{13}$. Esta cortesía social puede explicarse a partir de lo que significó en los fastos de la coronación de Quintana como poeta nacional (15-III-1855) la publicación de la Corona poética dedicada al Excmo. Sr. D. Manuel José Quintana con motivo de su coronación (1855), volumen fabricado e impreso por $L a$ España Musical y Literaria, empresa periodística en la que José Marco era pieza fundamental. En este volumen celebratorio aparecieron "bellísimas poesías de nuestros jóvenes poetas" como anunciaba el diario progresista La Nación (7-IV-1855), poetas como Antonio Arnao, Gustavo Adolfo Bécquer, José María de Larrea, Juan Antonio de Biedma y varias mujeres entre las cuales figura María del Pilar Sinués y Navarro, que firma una oda en octavas reales escrita en Zaragoza.

Las relaciones editoriales de Marco y el grupo de sus amigos tejen la primera red de acogida para la escritora aragonesa; Marco, además, era funcionario público y como recuerda Nombela "siguió ascendiendo en el ministerio de Ultramar". Juan Antonio de Viedma escribió un elocuente prólogo para el poemario de Pilar Cantos de mi lira (Madrid, 1857); la revista Album de señoritas y Correo de la Moda, con la que Bécquer tuvo estrecha vinculación, publicó una "Fábula"14 suya y la poeta zaragozana cantará al escultor valenciano José Piquer, relacionado con su esposo, en una "Oda con motivo de la estatua de Colón" (La Época, 5-XI1860). La estrategia de legitimación matrimonial (Sánchez Llama, 1999, p. 275) sirvió para el acomodo de la escritora en la sociedad literaria madrileña, pero sus propias habilidades y el trenzado de otros filamentos enriquecieron la trama de su consolidación literaria, como se verá a continuación.

\section{LA FABRICACIÓN DE LA FAMA}

Una vez establecida en la Corte, el nombre de Pilar Sinués aparece con frecuencia en las publicaciones periódicas madrileñas a partir de 1857 , bien como autora de textos propios, bien en noticias sobre sus publicaciones o sus actividades particulares. La capital del Reino va a ser la meta de salida de su intensa actividad de escritora confirmando en su caso lo que había afirmado Enrique Pérez Escrich en 1873: "Madrid es el sueño dorado del poeta de provincias" ${ }^{15}$, un sueño urbano que, como ocurría en el París del balzaquiano Lucien de Rubempré, abría los escalones para el éxito social y la gloria artística y un escenario que inició su despliegue a partir de la vergonzante bohemia del Madrid de mediados de siglo (Romero Tobar, 1993). Este fue el marco en el que se insertó nuestra autora y del que supo sacar muchas de sus posibilidades.

Las convenciones sociales de la época fijaban con precisión cuáles eran los limitados espacios en los que se podían desenvolver las mujeres frente a la soltura con la que se movían los escritores varones. Las relaciones personales y, consecuentemente, los contactos profesionales para los escritores se desplegaban en múltiples escenarios. Por supuesto, las redacciones de los periódicos donde el trabajo y las tertulias consumían horas sin cuento y en donde no participaban 
las mujeres ${ }^{16}$. Otro lugar imprescindible lo fijaban las tertulias de café, lugar al que las mujeres solo podían acudir acompañadas, ya que su asistencia sin acompañamiento masculino era nota de su condición peripatética. Las salas de profesores y las buhardillas o las habitaciones de pensiones económicas también interrelacionaban a los artistas varones entre ellos, que, además, representaban un papel coral en los salones de sociedad, lugar este último al que sí les estaba permitido acudir a las féminas.

Las varias funciones que cumplían los encuentros de hombres y mujeres en los salones domésticos, abiertos en determinadas ocasiones a quienes hubieran sido admitidos expresamente, son suficientemente conocidas gracias a las monografías que se han dedicado al estudio de la divulgación musical (Alonso González, 1997), a las exhibiciones pictóricas o a las lecturas literarias (Román y Palenque, 2008; Ezama, 2006), a la del poder de los huéspedes que recibían a sus invitados y, por supuesto, a la de las jóvenes que iniciaban su carrera de merecimientos. Pilar Sinués hizo amplio uso de esta última función en sus novelas, sirva el testimonio de una:

(Isabel casada con el marqués de Santa Fe) "Cuando ya la vio enteramente tranquila la presentó en el gran mundo y bien pronto se hizo notable en los círculos aristocráticos por su rara y seductora belleza y por el buen gusto y extraordinaria riqueza con que siempre se ataviaba; los más elegantes jóvenes, los hombres más distinguidos se apresuraron a ofrecerla sus homenajes y su cándida virtud convirtió en pasiones verdaderas muchas de aquellas frívolas galanterías" (Margarita, pp. 106-107).

Salvo que el titular del salón fuera una dama, no eran los salones el lugar más idóneo para los éxitos literarios de las mujeres, ya que la connotación de extravagantes solía ir aparejada a las lecturas públicas de textos escritos por autoras del género femenino. A vía de ejemplo, Emilia Pardo Bazán, cuyo papel social en el Madrid de la Restauración está fuera de dudas, encontró dificultades para ser admitida en los salones dada su condición de "literata" según recuerda Melchor Almagro Sanmartín (s.a.): "Con su pluma y su talento abrióse doña Emilia las puertas del mundo político y literario". Sus batallas para entrar en los salones aristocráticos, lugar donde reinan las féminas, fueron más difíciles al presentarse nimbada de su gloria literaria que si hubiera simplemente exhibido los pasaportes de su catolicismo e hidalguía de sangre" (p. 164).

Las prédicas moralizantes de los textos de la Sinués tuvieron que ayudarle en su aceptación por los cen- sores eclesiásticos y los órganos administrativos que eran decisorios en la educación pública. La colección de relatos que responden al título de La ley de Dios $(1858)^{17}$ y $A$ la luz de una lámpara recibieron protección expresa de las autoridades eclesiásticas y las educativas del Estado (Sánchez Llama, 2000, pp. 329330). Claro que a la moralina expresa que rezumaban sus cuentos y novelas se sumaba su camaleonismo redaccional, como ocurre en la transformación que verifica de los personajes masculinos de la colección de cuentos alemanes del P. Schmid cuando los tradujo del francés en 1883 bajo el título de Cuentos para niñas (Hibbs-Lissorgues, 2008).

Pero el instrumento que más debió ayudar a la expansión de su fama fue la buena relación que mantuvo con los medios periodísticos. No en vano, El Fénix de 8 de enero de 1858 publicaba la noticia-reclamo de que doña Pilar Sinués había cedido sus novelas un real más barato a los lectores de este diario. Este periódico, en el curso de su publicación (años 1857-1859), dedicó gacetillas varias a nuestra autora entre las que no es desdeñable la que informaba de haber sido recibida en audiencia particular por los reyes de España (El Fénix, 10-XI-1858) o cómo el día de San Antonio en una reunión artística en casa de don Antonio Retondo habían leído poesías los señores Ivo Alfaro, Bretón de los Herreros, Bravo, José Marco, Miguel Agustín Príncipe, Santistevan y doña Pilar Sinués (El Fénix, 15$\mathrm{VI}$-1858). Las revistas femeninas y de contenido literario le abrieron sus páginas pero, en el orden de su proyección periodística, el dato más significativo es su vinculación con El Imparcial desde el mes de enero de 1875 hasta el mismo mes de 1891 (Simón Palmer, 1991, pp. 664-671).

No me consta que Pilar Sinués tuviera abierto un salón literario, aunque como he adelantado más arriba las reuniones de salón eran episodios frecuentes en sus novelas. En La senda de la gloria, por ejemplo, construye los tipos de dos mujeres dedicadas a la creación artística, la pintora Julia y la escritora Clemencia. En esta obra las reuniones artísticas de salones tienen un papel importante tanto en la descripción de los ambientes como en la reconstrucción de los diálogos que preceden y siguen a las lecturas de textos. Momento singular es el de la sesión artística descrita en el capítulo IV del libro quinto ("La gloria") y la tertulia cafeteril que, al día siguiente, comenta el acontecimiento en términos que contraponen la visión masculina -"ni una palabra entiendo de versos, me gustaron, sin embargo, más los de la marquesa, porque los lee con mucho más descaro" dice un va- 
rón- a la perspectiva femenina que elogia la actuación de Clemencia, cuya presencia idealizada y su lección poética, moralmente ejemplar, suscitó en las mujeres oyentes este deseo: "iQué dichosa sería yo si quisiera ser mi amiga!- Tal fue el triunfo de Clemencia, y tal es el juicio de la que esto escribe; la verdadera, la única gloria a que deben aspirar el talento y el decoro reunidos en una mujer".

La lección moral de esta novela reside en la idea, de índole autobiográfica, de que escribir es una de las mejores tareas para la educación social de la mujer, tarea que pueden cumplir también las mujeres. Un resumen del proyecto educativo-social en el que la escritora Zaragozana estuvo comprometida desde su infancia, como afirma en la dedicatoria de esta obra "Al público":

Mi pobre persona es para ti tan conocida, ioh público amigo!, que por doquiera que paso te oigo pronunciar mi nombre; y uniendo acaso entonces en tu mente la figura infantil de la autora con las sombrías verdades que encierra esta lastimera historia, tu interés se despertó a favor mío. Yo te doy las gracias, amigo complaciente, mi primero, y quizá mi único amigo.

\section{APÉNDICE}

\section{Al ilustre poeta Don Manuel José Quintana}

Del Ebro la ribera caudalosa

Me vio nacer, como la flor lozana

Que acaricia la noche misteriosa

Y abre el primer albor de la mañana.

A mi cuna cual música armoniosa

Llegó el eco del nombre de QUINTANA.

$Y$ desde entonces vive en mi memoria

Como el único ensueño de mi gloria.
Crecí después, y al escuchar las notas

De tu cantar, creíme trasportada

A las regiones del saber ignotas

Y del amor á la mansión dorada.

Aún viven en mi mente las remotas

llusiones del alma enamorada.

$Y$ aún te bendice quien tu triunfo abona

Y estas flores añade a tu corona.

¡Salud, oh noble anciano virtuoso!

¡Salud, vate en mi patria bendecido!

Claro sol, inmortal y esplendoroso,

Que rasgará las nieblas del olvido.

¡Salud mil veces, sí, pues que amoroso

La tierna juventud has dirigido.

Y empleaste tu pluma y tu existencia

En guiarla al alcázar de la ciencia!

Yo te saludo, sí, desde mi infancia

Te consagré mi amor y mi ternura,

Que la niña en su cándida ignorancia

Amaba del saber la fuente pura.

Recibe de mis flores la fragancia;

Pobres serán, mas llenas de frescura.

Yo las cogí de abril una mañana

Para enlazar el nombre de QUINTANA.

María del Pilar Sinués y Navarro.

Zaragoza 
1 El año 1876 se publican dos volúmenes de la autora -Un libro para las damas y Combates de la vida- cuyo nombre aparece en la portada sin el "de Marco" que encontramos en los editados con anterioridad. Varios estudiosos de la autora, a falta de documentos acreditativos, han apuntado que la instalación de Pilar Sinués en París el año 1875 como corresponsal de El Correo de la Moda sería una pista que acreditase la separación matrimonial. Comoquiera que sea, el análisis de las obras que publicó después de la Restauración (1876) muestra una deriva intencional a favor de la autonomía femenina.

2 El Ángel del Hogar es el título de un libro de la autora editado en 1859 que tuvo siete ediciones, todas encaminadas hacia la admonición sobre el comportamiento social de las mujeres. No debe confundirse esta obra programática con el periódico del mismo título que Pilar Sinués dirigió y editó entre los años 1864 y 1869. La fórmula ángel del hogar se ha convertido en rótulo inevitable en los estudios de género del ámbito hispánico a partir del madrugador libro (1991) de Briget Aldaraca dedicado a la ideología de la domesticidad en la narrativa galdosiana.

3 Aunque se echa en falta un repertorio bibliográfico completo de la producción de esta autora, las más fiables fuentes informativas son los repertorios de $\mathrm{Pa}$ lau y Dulcet (1969, XXI, pp. 294-299) y Carmen Simón (1991, pp. 650-672) y, por descontado, las monografías que le han dedicado íñigo Sánchez-Llama (1999; 2000, pp. 325-371 y 2002) y las estudiosas citadas en nota 4 . Ninguno de los autores mencionados han citado las primeras ediciones de varias obras de la autora, que solo se conocen a partir de la segunda edición.

4 En la interpretación del lugar ocupado por Pilar de Sinués en el gineceo literario de la ideología de la domesticidad han aportado observaciones pertinentes Íñigo Sánchez Llama fundamentalmente y también Solange Hibbs-Lissorgues, Catherine Jagoe, Ana María Navales y María Cristina Urruela, entre otros.

5 La voz narradora manifiesta en el capítulo $\mathrm{V}$ de la segunda parte de Margarita: "Detrás del hermoso paseo llamado Salón de San Francisco, se eleva el convento de Santa Rosa; aunque sus paredes son altas y su fachada vetusta y antigua, nada tiene su aspecto de melancólico o sombrío. ¡Salud, albergue santo, donde pasé alegre las mejores horas de mi infancia! ¡Mansión tranquila y apacible, salud! ¡Aún en este instante salta mi corazón de placer, al transportarme en alas de mi imaginación dentro de tus muros!" (p. 58)

6 Juan Miguel de Losada en su prólogo a la novela Fausta Sorel (1861) indica que Pilar había asistido al convento de Santa Rosa como educanda.

7 La propia autora recordaría en ocasiones haber iniciado su actividad literaria a los nueve años (en la dedicatoria de la segunda edición de La senda de la gloria, 1880).

8 Op. cit., pp. 76-77.

9 En páginas de publicidad al final de $E$ Ángel del Hogar (1859) se enumeran un corpus de dos libros de poesía, un drama, dos volúmenes de leyendas históricas y cuatro novelas (Sánchez Llama, 2002, p. 329)

10 Juan Miguel de Losada reconoce la impronta de Balzac en su extenso prólogo a Fausta Sorel (1861): "Hay en esta novela algo de mano maestra, la señora Sinués de Marco quiere seguir las huellas de Balzac" (p. XIII).
11 En el orden de las dedicatorias, téngase en cuenta que la de su primer libro estaba enderezada a Zaragoza, "pueblo invicto, objeto de mi afecto más cumplido".

12 Manuscrito de la Biblioteca Nacional de Madrid (Mss. 4013/1/14), una carta a Eusebio Blasco en la que Pilar Sinués comenta con proximidad amistosa las tendencias políticas progresistas de su cuñado y la relación amistosa de su madre y la del también aragonés Eusebio Blasco.

13 Texto editado en Quintana (1969, p. 393).

14 Pageard (1990, pp. 142-143) subrayó la presencia de varias escritoras aragonesas en esta revista.

15 "El saloncillo del teatro del Príncipe", en Blasco (1873, p. 23).

16 Manuel Bretón de los Herreros estrenó en 1836 la comedia La redacción de un periódico en la que su protagonista femenina -hija del propietario del periódico- solo puede acudir a la sala de redacción muy brevemente.

17 Los datos de la portada de este libro son suficientemente expresivos de la red de relaciones sociales que había trabado la escritora. Las diez leyendas estaban "basadas en los preceptos del decálogo", el volumen iba precedido de un prólogo firmado por el presbítero Antonio Navarro Asensio, estaba dedicado a la infanta doña María Isabel Francisca de Asís y "por Real Orden de 26 de abril de 1860, ha sido aprobada de testo [sic] esta obra para las escuelas de instrucción primaria y justipreciada en 28 reales cada ejemplar". 
AA. VV. (1988). Enciclopedia temática de Aragón (vol 7. Literatura). Zaragoza: Moncayo.

Agudo Catalán, S. (2008). El Romanticismo en Aragón (1838-1854). Literatura, prensa y sociedad. Zaragoza: Prensas Universitarias de Zaragoza.

Alas, L. Clarín (2002). Obras Completas (vol. V. Artículos (1875-1878)) (edición de Yves Lissorgues y Jean François Botrel). Oviedo: Nobel.

Almagro San Martín, M. (s.a.). Bajo los tres últimos Borbones (Retratos, estampas e intimidades). Madrid: Afrodisio Aguado.

Alonso González, C. (1997). La canción lírica española en el siglo XIX. Madrid: Instituto Complutense de Ciencias Musicales.

Blasco, E. (1873). Madrid por dentro y por fuera. Guía de forasteros incautos. Madrid: J. Peña.

Ezama Gil, Á. (2006). "Valera y las damas licurgas". En Bonilla Cerezo, R., Costa Palacios, A. y Sánchez Montero, E. (eds.). Juan Valera (1905-2005). Actas del II Congreso Internacional celebrado en Cabra (Córdoba) los días 27, 28, 29, 30 de abril y 1 de mayo de 2005. Cabra: Delegación de Cultura, pp. 125-150.

Ezama Gil, Á. (2007). “Emilia Pardo Bazán, revistera de salones: teoría y praxis de la crónica". Especulo, 37, 14 de noviembre de 2007.

Guía de Zaragoza... (1860). Zaragoza: Imprenta de Vicente Andrés.

Hibbs-Lissorgues, S. (2008). "Escritoras españolas entre el deber y el deseo. Faustina Sáez de Melgar (1834-1895), Pilar Sinués de Marco (1835-1893) y Antonia Rodríguez de Ureta". En Fernández, P. y Ortega, M.L. (eds.). La mujer de letras o la letraherida. Discurso y representacio- nes sobre la mujer escritora en el siglo XIX. Madrid: Consejo Superior de Investigaciones Científicas, pp. 325-343.

Jagoe, C. (1993). "María Pilar Sinués de Marco (1835-1893)". En Gould Levine, L., Marson, E. y Waldman, G. (eds.). Spanish Women Writers. A Bio-Biographical Source Book. London: Greenwood Press, pp. 473-483.

Navales, A.M. (1977). “María Pilar Sinués, escritora zaragozana del siglo XIX", $\mathrm{He}$ raldo de Aragón, 12 de octubre de 1977.

Nombela, J. (1976). Impresiones y recuerdos (introducción de Jorge Campos). Madrid: Tebas.

Pageard, R. (1990). Bécquer, leyenda y realidad (introducción de Hans Juretschke). Madrid: Espasa-Calpe.

Palau y Dulcet, A. (1969). Manual del librero hispanoamericano. Bibliografía general española e hispanoamericana desde la invención de la imprenta hasta nuestros tiempos (vol. XXI). Barcelona.

Quintana, M.J. de (1969). Poesías Completas (edición de A. Dérozier). Madrid: Castalia.

Román Gutiérrez, I. y Palenque, M. (2008). Pintura, literatura y sociedad en la Sevilla del siglo XIX: el álbum de Antonia Díaz. Sevilla: Diputación Provincial de Sevilla.

Romero Tobar, L. (1976). La novela popular española del siglo XIX. Madrid: Ariel -Fundación Juan March.

Romero Tobar, L. (1993). "En los orígenes de la bohemia: Bécquer, Pedro Sánchez y la revolución de 1854". En Piñero, P.M. y Reyes, R. (eds.). Bohemia y literatura. De Bécquer al Modernismo. Sevilla: Universidad de Sevilla, pp. 27-49.
Romero Tobar, L. (2003). “El campo de la producción intelectual”. En Infantes, V. Lopez, F. y Botrel, J.F. (eds). Historia de la edición y de la lectura en España 1472-1914. Madrid: Fundación Germán Sánchez Ruipérez, pp. 531-542.

Sánchez Llama, I. (1999). “María Pilar Sinués de Marco y la cultura oficial peninsular del siglo XIX: del neocatolicismo a la estética realista". Revista Canadiense de Estudios Hispánicos, XXIII, 2, pp. 271288.

Sánchez Llama, I. (2000). Galería de escritoras isabelinas: la prensa periódica entre 1833 y 1895. Madrid: Cátedra, pp. 325-371

Sánchez Llama, I. (2002). Antología de la prensa periódica escrita por mujeres (1843-1894). Cádiz: Universidad de Cádiz.

Simón Palmer, M.C. (1991). Escritoras españolas del siglo XIX. Manual bio-bibliográfico. Madrid: Castalia.

Sinués, P. (1959). El Ángel del Hogar. Obra moral y recreativa dedicada a la mujer y escrita por la señora doña María del Pilar Sinués de Marco. Madrid: Imprenta y Esterotipia de los Sres. Nieto y Compañía, segunda edición corregida, aumentada e ilustrada con láminas.

Urruela, M.C. (2001). "Becoming angelic: María del Pilar Sinués and the woman question". En Vollendorf, L. (ed.). Recovering Spain's feminist tradition. New York: Modern Language Association of America, pp. 160-175.

Urruela, M.C. (2005). “El ángel del hogar: María Pilar Sinués y la cuestión de la mujer". En Vollendorf, L. (ed.). Literatura y feminismo en España (siglos XVXXI). Barcelona: Icaria, pp. 155-169. 